\title{
1-Phosphatidylinositol 4,5-Bisphosphate Phosphodiesterase Gamma-2
}

National Cancer Institute

\section{Source}

National Cancer Institute. 1-Phosphatidylinositol 4,5-Bisphosphate Phosphodiesterase

Gamma-2. NCl Thesaurus. Code C18942.

1-phosphatidylinositol 4,5-bisphosphate phosphodiesterase gamma-2 (1265 aa, 148

$\mathrm{kDa}$ ) is encoded by the human PLCG2 gene. This protein plays a role in second

messenger molecule biosynthesis. 